Article

\title{
Do People Place More Value on Natural Gas Than Coal for Power Generation to Abate Particulate Matter Emissions? Evidence from South Korea
}

\author{
Hyo-Jin Kim, Ju-Hee Kim and Seung-Hoon Yoo * (D) \\ Department of Energy Policy, Graduate School of Energy \& Environment, Seoul National University of \\ Science \& Technology, 232 Gongreung-Ro, Nowon-Gu, Seoul 01811, Korea; \\ hjinkim@seoultech.ac.kr (H.-J.K.); jhkim0508@seoultech.ac.kr (J.-H.K.) \\ * Correspondence: shyoo@seoultech.ac.kr
}

Received: 17 March 2018; Accepted: 15 May 2018; Published: 25 May 2018

\begin{abstract}
As of 2017, coal is responsible for about half of all power generation in South Korea, while natural gas (NG) is responsible for about $20 \%$. This increases particulate matter (PM) emissions, as coal emits 6 to 55 times more PM than NG in the course of power generation. Increased PM concentration causes visibility impairment and acute respiratory diseases. Thus, the South Korean government is seeking to shift from coal to NG power generation for the purpose of abating PM emissions. The government also considers NG as a bridge energy to facilitate the transition from fossil fuels to renewable energy. This article attempts to answer the question, "Do people place significant value on shifting from coal to NG power generation in order to abate PM?" To this end, additional willingness to pay (WTP) for NG over coal for electricity for the purpose of PM emissions abatement was assessed from 1000 South Koreans' contingent valuations (CV). More specifically, each of these randomly chosen interviewees was asked about her/his WTP for the switch from coal to NG for $1 \mathrm{kWh}$ of electricity use. The average additional WTP estimate was KRW 31.27 (USD 0.028) per $\mathrm{kWh}$, which is equivalent to $28.8 \%$ of the average price of electricity in 2017 . Moreover, this estimate is statistically significant. The generation cost of NG is about KRW 100.13 per kWh, which is higher than that of coal (KRW 78.5 per kWh). The gap is KRW 22.08 per kWh, which is less than the additional WTP. Thus, it is obvious that the governmental policy of shifting from coal to NG for power generation in order to abate PM emissions is supported by the public and, hence, the shift should be made gradually.
\end{abstract}

Keywords: coal; natural gas; power generation; shift; particulate matter; willingness to pay; contingent valuation

\section{Introduction}

In 2017, about half of electricity generation came from coal-fired generations in South Korea [1]. This causes a severe problem of increasing emissions of particulate matter (PM), such $\mathrm{PM}_{10}$ and $\mathrm{PM}_{2.5}$ that are harmful to the human body and produce visibility impairment. According to the Korean Ministry of Environment, the amount of PM emissions emitted from coal-fired generations accounted for more than half of PM that was produced by industrial facilities for massive PM discharge [2]. On the other hand, natural gas (NG) generation was responsible for about $20 \%$ of electricity generation in 2017. NG can be a useful alternative to coal as a generation source in terms of abating PM. It is known that the amount of air pollutant emissions from coal-fired electricity generation is much larger than that from NG-fired electricity generation. The amount of PM emissions from coal-fired generation is about six to fifty-five times greater than that of NG-fired generation [3]. 
The World Health Organization announced that seven million people have died prematurely because of PM [4]. In 2013, PM was classified as a Group One carcinogen, which are identified as factors causing cancer to humans [5]. Unlike ordinary dust particles that float in the air, PM particles that have a diameter of $10 \mu \mathrm{m}$ or less are too small to be filtered by the nose or bronchial tubes and are accumulated in the body, causing various diseases [6-9].

Particles that have a diameter ranging from 2.5 to $10 \mu \mathrm{m}$ are called $\mathrm{PM}_{10}$ (fine dust), and particles that have a diameter smaller than $2.5 \mu \mathrm{m}$ are named $\mathrm{PM}_{2.5}$ (ultrafine dust). $\mathrm{PM}_{2.5}$ is more dangerous than $\mathrm{PM}_{10}$ because it easily penetrates deep into the human body. $\mathrm{PM}_{2.5}$ can reach the alveoli through the nose and airways during breathing and can infiltrate the blood vessels and cause inflammation $[10,11]$. In this process, the blood vessels are damaged, which increases the risk of developing angina and suffering a stroke.

Furthermore, at the same concentration, $\mathrm{PM}_{2.5}$ has a larger surface area than $\mathrm{PM}_{10}$ and, thus, it can adsorb more harmful substances. The findings from some studies indicate that long-term exposure to $\mathrm{PM}_{2.5}$ augments the mortality rate of cardiovascular and respiratory illnesses by $6-13 \%$, as $\mathrm{PM}_{2.5}$ concentration increases by $10 \mu \mathrm{g}$ per $\mathrm{m}^{3}[12,13]$. The elderly, children, pregnant women, and those with heart and circulatory diseases are more vulnerable to $\mathrm{PM}_{2.5}$ exposure than ordinary people. Air quality problems, including high concentrations of $\mathrm{PM}_{2.5}$, significantly negatively affect the health of citizens in urban areas [14].

As the PM emitted from coal-fired generation has recently increased in South Korea, there is serious concern around the damage that is causing to the health of the general population. In particular, on the morning of 21 March 2017, Seoul, the capital of South Korea, where about 25\% of the national population lives, experienced the second worst air quality of the world's major cities [15]. Moreover, South Korea's average $\mathrm{PM}_{2.5}$ exposure was $32.0 \mu \mathrm{g}$ per $\mathrm{m}^{3}$ in 2015 - the worst among 35 OECD countries. Furthermore, it was more than double the OECD countries' average $\mathrm{PM}_{2.5}$ exposure in the same year $\left(14.5 \mu \mathrm{g} / \mathrm{m}^{3}\right)$ [16].

In South Korea, the generation capacity of the NG-fired power plants is almost equal to that of the coal-fired power plants, however the amount of electricity generated from NG, which discharges much less PM than coal, is only half as much as that of coal. Thus, the government is seeking to shift from coal-fired generation to NG-fired generation for the purpose of abating PM emissions. Moreover, the government also considers NG as the bridge energy to facilitate the transition from fossil fuels to renewable energy. However, the shift entails a higher production cost of electricity which will raise the average price of electricity. Moreover, government officials are asking information about the value that the enforcement of the policy shift will bring for the public. Knowing this will help the government officials understand whether the shift should be performed or not.

This article tries to answer the question, "Do people place significant value on shifting from coal to NG for power generation in order to abate PM?" To this end, additional willingness to pay (WTP) for NG over coal for electricity, for the purpose of PM emissions abatement, was derived from 1000 South Koreans' contingent valuations (CV). More specifically, randomly chosen interviewees were asked about her/his WTP for the switch from coal to NG for $1 \mathrm{kWh}$ of electricity use. The rest of this article is composed of four sections. Section 2 explains the methodology that this article adopts. Section 3 describes modeling of the WTP data. Finally, Section 4 provides the results and a discussion of these results. The final section presents the conclusions.

\section{Methodology}

\subsection{Object to Be Evaluated}

As addressed above, increasing PM emissions in South Korea has become a critical problem, and effective and rigorous policies should be taken to abate PM emissions. Thus, the government seeks to increase gas generation by reducing coal generation. The improvement goal of the presented policy is to abate PM emissions emitted from coal-fired generation by switching from coal to NG for power generation. 
The policy instrument, which was conveyed and explained to the respondents during the CV survey through the use of newspaper articles, color pictures, and well-made presentation materials, is to consume $1 \mathrm{kWh}$ of electricity produced from NG over coal. Thus, the government requires quantitative information about the public WTP for the switch. This article attempts to examine the additional WTP for the shift from coal to NG for power generation, with a view to abating PM emissions.

\subsection{Method: $\mathrm{CV}$}

Following a literature review, it was found that stated preference (SP) methods have often been applied when measuring the public's WTP. SP methods usually ask people to state their WTP for consuming the goods or services concerned. Two representative approaches belonging to SP methods are the CV approach and the choice experiment (CE) approach [17-23]. The former elicits the WTP response directly, whereas the latter derives the WTP responses indirectly. This study will employ the $\mathrm{CV}$ approach rather than the $\mathrm{CE}$ approach, because the first is much simpler to apply than the second, and the attributes required to use the CE approach are not well defined in this study.

Our research can be compared with previous researches in at least four aspects. First, studies that investigate the role of NG to abate PM emissions compared with that of coal, remain scarce as most of the related studies have tackled PM itself [24-29]. Considering this, the present study can contribute to the literature on the additional WTP for electricity from NG-fired generation over coal-fired generation in view of PM emissions abatement. In particular, there is no former research that investigated the public WTP for consuming $1 \mathrm{kWh}$ of electricity produced from NG over coal to abate PM emissions in South Korea or other countries.

Second, our application of the CV technique coincides with the practice adopted in the former studies that dealt with this kind of research topic. Moreover, the CV technique is based on microeconomics and, thus, is theoretically sound [30]. Since the findings obtained in this article can be used in policy-making and analysis, it is crucial to use reasonable and sound methodology. The CV technique is not only practically useful but also theoretically robust.

Third, we tried to follow several recommended guidelines in the literature for applying the CV approach. These include the use of a dichotomous choice (DC) question, a minimum sample size of 1000 , the announcement of the possible presence of substitutes for the goods to be investigated in the $\mathrm{CV}$ survey, and so on. More details will be presented in the next subsections.

Fourth, when eliciting the WTP responses, this study paid more attention not only to mitigating the response bias, but also to augmenting the statistical efficiency. This article employs a single-bounded (SB) DC method described by Hanemann [31], which produces less response bias than the double-bounded (DB) DC method. Furthermore, the spike model proposed by Kriström [32] is combined with the SB DC method in order to model the WTP data with zero observations.

\subsection{Sampling and Survey Questionnaire}

A total of 1000 interviewees were sampled nationwide on the basis of the demographic characteristics reported by Statistics Korea [33]. Our sampling method was stratified random sampling. The entire process of sampling and carrying out the survey was administered by a professional polling company during June 2017. The firm sought to make sure that the sample characteristics were a good representation of the population characteristics. An experienced specialist at the firm ran the whole process.

A pretest using a focus group of thirty people was implemented with an earlier version of the survey instrument to examine whether it was understandable and clear enough for the interviewees to finish filling in the survey questionnaire. The outcomes of the in-depth interviews with the focus group were then utilized to make sure that the questionnaire for the main survey was suitable. The final modified version of the survey questionnaire is made up of four parts. The first part presents the background and objective of the survey. The second part includes several questions about the interviewees' opinions and judgment regarding the shift from coal-fired generation to NG-fired generation. The third part deals with questions concerning the additional WTP for consuming $1 \mathrm{kWh}$ 
of electricity produced by NG over coal to abate PM emissions. Some questions about the respondents' characteristics were asked in the final part.

\subsection{Elicitation of WTP}

As explained above, this article adopted a SB DC question with the goal to elicite WTP responses. The DC question was originally recommended for the use in the field of CV surveys by a number of studies. The main reason for the recommendation is that it can reduce the respondents' burden of answering the WTP question and derive an incentive-compatible response from interviewees [31]. The DC question is relatively simple, and the respondents only need to reply with "yes" or "no" to a given bid amount. In this study, the respondents would report "yes" if her/his additional WTP for consuming $1 \mathrm{kWh}$ of electricity produced from NG-fired generation over coal-fired generation is more than or equal to an offered bid and "no" otherwise. On the other hand, an open-ended question which directly asks the WTP value is not preferred to the DC question in the literature, as the former can induce a number of protest WTP responses [30,34,35]. Most of the CV studies that adopt the DC question have applied the SB or the DB DC formats. The SB DC format has the merit of alleviating any response bias that might arise from the use of the DB DC format.

One complication involved in applying the CV is that it puts people in a hypothetical situation and, thus, the respondents can have difficulty stating their true WTP. An appropriate payment can help the respondents who are confronted with the hypothetical situation to report their WTP, making them feel as if they were in the real world. Some examples of the payment vehicle include a tax, such as income tax or property tax, a donation, a fund, a usage fee, and so on. The payment vehicle should be directly related to the object that is being evaluated and should be familiar to people. We decided that the payment vehicle that meets these two conditions is electricity bills. Thus, the WTP question presented to the respondents was, "Would you accept an increase in electricity bills as a result of shifting coal to NG for power generation to abate PM emissions?"

\section{WTP Model}

\subsection{SB DC Model}

Hanemann [31] proposed an approach to model the SB DC CV data which we adopted for our purposes. Before implementing the field CV survey, we needed to determine a set of bids. A bid is randomly selected from several bids and is presented to each interviewee. The symbol $A_{j}$ is defined as a bid presented to respondent $j$. The interviewees were asked to say "yes" or "no" to the payment of bid $A_{j}$, and an additional question is not required. Let $Y_{j}$ be the interviewee's WTP. Two responses, "yes" $\left(Y_{j} \geq A_{j}\right)$ and "no" $\left(Y_{j}<A_{j}\right)$, can emerge from the situation where $A_{j}$ is offered. Therefore, let $I_{j}^{Y}$ and $I_{j}^{N}$ be binary variables which correspond to the two kinds of responses. For instance, $I_{j}^{Y}$ is one if the jth interviewee reports "yes", and zero otherwise.

\subsection{Combination of SB DC Question and Spike Model}

An additional question, "Would your household agree to pay anything?", was given to the respondents who stated "no" to the bid. Her/his WTP was less than the bid and more than zero if the answer was "yes." Her/his WTP was zero if the answer was "no." One more binary variable, $I_{j}^{T Y}$, was defined as one if the answer was "yes" and zero otherwise. Thus, there were three outcomes:

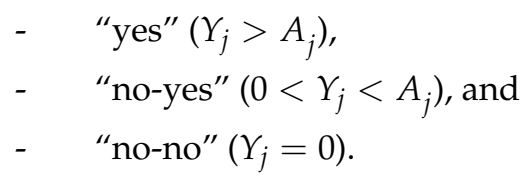

As will be explained below, out of the 1000 respondents, 328 said that they had no intention of paying a penny. Thus, the spike model can be employed to deal with the WTP data. Considering that 
the most frequently used distribution in analyzing the DC CV data is logistic distribution, we specify the WTP distribution function, $F_{Y}(\cdot)$, as:

$$
F_{Y}\left(A ; \gamma_{0}, \gamma_{1}\right)= \begin{cases}{\left[1+\exp \left(\gamma_{0}-\gamma_{1} A\right)\right]^{-1}} & \text { if } A>0 \\ {\left[1+\exp \left(\gamma_{0}\right)\right]^{-1}} & \text { if } A=0 \\ 0 & \text { if } A<0\end{cases}
$$

where $\gamma_{0}$ and $\gamma_{1}$ are the parameters of $F_{Y}(\cdot)$.

The log-likelihood function we deal with is:

$$
\begin{aligned}
\ln L= & \sum_{j=1}^{S}\left\{I_{j}^{Y} \ln \left[1-F_{Y}\left(A_{j} ; \gamma_{0}, \gamma_{1}\right)\right]\right. \\
& +I_{j}^{T Y} \cdot I_{j}^{N} \ln \left[F_{Y}\left(A_{j} ; \gamma_{0}, \gamma_{1}\right)-F_{Y}\left(0 ; \gamma_{0}, \gamma_{1}\right)\right] \\
& \left.+\left(1-I_{j}^{T Y}\right) \cdot I_{j}^{N} \quad \ln F_{Y}\left(0 ; \gamma_{0}, \gamma_{1}\right)\right\}
\end{aligned}
$$

where $S$ is the sample size.

We can get the estimates for $\gamma_{0}$ and $\gamma_{1}$ by finding the values for $\gamma_{0}$ and $\gamma_{1}$ maximizing Equation (2), that is, using the maximum likelihood estimation method. When using Equation (1) and the estimates for $\gamma_{0}$ and $\gamma_{1}$, the average WTP can be obtained as:

$$
E(Y)=\int_{0}^{\infty}\left[1-F_{Y}\left(A ; \gamma_{0}, \gamma_{1}\right)\right] d A-\int_{-\infty}^{0} F_{Y}\left(A ; \gamma_{0}, \gamma_{1}\right) d A=\left(1 / \gamma_{1}\right) \ln \left[1+\exp \left(\gamma_{0}\right)\right]
$$

\section{Results and Discussion}

\subsection{Data}

When the survey was carried out, USD 1.0 was equivalent to KRW 1125. The list of bids used in the CV survey was KRW 10, 20, 30, 40, 60, 80, and 100. They were determined through the focus group interview of thirty individuals as follows: first, we asked the WTP for the enforcement and obtained a set of WTP values; second, we deleted zero WTP values and then sorted the remaining positive WTP values to look into empirical distribution; third, some bids were selected from the distribution. One of the seven bids was randomly provided to the interviewees.

Finally, 1000 useable observations were obtained from the CV survey. Table 1 reports a summary of the interviewees' responses to each bid. Overall, 319, 353 and 328 interviewees gave "yes", "no-yes", and "no-no" responses, respectively. Out of the 1000 respondents, 328 said that they had no intention of paying a penny ("no-no" responses).

Table 1. Summary of the interviewees' responses.

\begin{tabular}{ccccc}
\hline \multirow{2}{*}{ Bid Amount a } & \multicolumn{3}{c}{ Number of Responses (\%) } & \multirow{2}{*}{ bample Size } \\
\cline { 2 - 4 } & “yes" & “no-yes" & “no-no" & \\
\hline 10 & $98(68.5 \%)$ & $22(15.4 \%)$ & $23(16.1 \%)$ & $143(100.0 \%)$ \\
20 & $77(53.8 \%)$ & $25(17.5 \%)$ & $41(28.7 \%)$ & $143(100.0 \%)$ \\
30 & $51(35.7 \%)$ & $50(35.0 \%)$ & $42(29.4 \%)$ & $143(100.0 \%)$ \\
40 & $30(21.0 \%)$ & $64(44.8 \%)$ & $49(34.3 \%)$ & $143(100.0 \%)$ \\
60 & $23(16.1 \%)$ & $64(44.8 \%)$ & $56(39.2 \%)$ & $143(100.0 \%)$ \\
80 & $22(15.5 \%)$ & $51(35.9 \%)$ & $69(48.6 \%)$ & $142(100.0 \%)$ \\
100 & $18(12.6 \%)$ & $77(53.8 \%)$ & $48(33.6 \%)$ & $143(100.0 \%)$ \\
Totals & $319(31.9 \%)$ & $353(35.3 \%)$ & $328(32.8 \%)$ & $1000(100.0 \%)$ \\
\hline
\end{tabular}

Notes: ${ }^{a}$ The unit is Korean won (USD $1.0=$ KRW 1125 at the time of the survey). ${ }^{b}$ The corresponding percentage of the sample is given in parentheses beside the number of responses. 


\subsection{Estimation Results}

Table 2 presents the estimation results of the model. The estimates for $\gamma_{0}$ and $\gamma_{1}$ are all statistically significant. In particular, the negative sign of the estimate for $\gamma_{1}$ means that higher bid amounts induce a lower possibility of reporting "yes" to an offered bid. From Equation (1), the spike is derived as $\left[1+\exp \left(\gamma_{0}\right)\right]^{-1}$. The estimate for the spike is calculated as 0.3399 and is statistically significant. Because the spike implies that there is the possibility of the interviewees' WTP being zero, the estimated spike should not be significantly different from the sample ratio of zero WTP $(32.8 \%)$. This is the case with our study.

Table 2 also provides an estimate of the average WTP calculated using Equation (3). The average WTP estimate has the value of KRW 31.27 (USD 0.028) per $1 \mathrm{kWh}$ and has statistical meaningfulness. It is desirable to calculate its confidence interval to explicitly take into account the uncertainty concerning the calculation of the point estimate. The $95 \%$ confidence interval, computed by adopting the bootstrapping technique presented in Krinsky and Robb [36], is KRW 28.63-34.12 (USD 0.025-0.030) per $1 \mathrm{kWh}$.

Table 2. Estimation results of the model.

\begin{tabular}{|c|c|}
\hline Variables & Estimates $^{d}$ \\
\hline Constant & $0.6638(9.84)^{\#}$ \\
\hline Bid amount ${ }^{a}$ & $-0.0345(-22.89){ }^{\#}$ \\
\hline Spike & $0.3399(22.46)^{\#}$ \\
\hline Mean additional WTP per $\mathrm{kWh}$ & KRW 31.27 (USD 0.028) \\
\hline$t$-value & $22.19^{\#}$ \\
\hline $95 \%$ confidence interval ${ }^{\mathrm{b}}$ & KRW 28.63 to 34.12 (USD 0.025 to 0.030 ) \\
\hline $99 \%$ confidence interval ${ }^{b}$ & KRW 27.79 to 35.08 (USD 0.025 to 0.031 ) \\
\hline Sample size & 1000 \\
\hline Log-likelihood & -1036.63 \\
\hline Wald statistic ( $p$-value $)^{\mathrm{c}}$ & $492.27(0.000)$ \\
\hline
\end{tabular}

Notes: ${ }^{a}$ The unit is KRW 1000, and the exchange rate was USD 1.0 = KRW 1125 at the time of the survey. ${ }^{\mathrm{b}}$ It was calculated using the bootstrapping technique given in Krinsky and Robb [36]. ${ }^{\mathrm{c}}$ It was computed under the null hypothesis of all the parameters' jointly being zero. ${ }^{\mathrm{d}}$ The values reported in parentheses beside the estimates are $t$-values; ${ }^{\#}$ denotes statistical significance at the $1 \%$ level.

\subsection{Reflection of Covariates}

Covariates refer to the factors that can have an effect on the probability of reporting "yes" to a given bid. Usually, the interviewees' characteristics are used as covariates, and the covariates are reflected in the model by inserting them into $\gamma_{0}$ in Equation (1). We considered four variables: gender, family, education, and income. The variables are explained in Table 3. Therefore, a positive sign of the coefficient for a variable implies that the bigger the value of the variable, the higher the possibility of reporting "yes" to a provided bid.

Table 3. Description of the variables used as covariates.

\begin{tabular}{cccc}
\hline Variables & Definitions & Mean & Standard Deviation \\
\hline Gender & The respondent's gender $(0=$ male; $1=$ female $)$ & 0.50 & 0.50 \\
Family & The size of the respondents' household (unit: persons) & 3.31 & 1.05 \\
Education & The respondent's education level in years & 14.23 & 2.28 \\
Income & The household's monthly income before tax (unit: million Korean won) & 4.40 & 2.01 \\
\hline
\end{tabular}

The estimation results of the model with covariates are presented in Table 4. The estimate for $\gamma_{1}$ is expected to have a negative sign. The coefficient estimates for the Education and Income variables were statistically significant, however, those for the Gender and Family variables were not. The respondent's education level was positively related to the probability of stating "yes" to a given bid. Similarly, wealthier interviewees were more inclined to accept the payment of an offered bid than less wealthy interviewees. 
Table 4. Estimation results of the model with covariates.

\begin{tabular}{lcc}
\hline \multicolumn{1}{c}{ Variables $^{\text {a }}$} & Estimates & $\boldsymbol{t}$-Values \\
\hline Constant & -1.7876 & $-4.28^{\#}$ \\
Bid amount ${ }^{\mathrm{b}}$ & -0.0357 & $-20.70^{\#}$ \\
Gender & 0.0881 & 0.71 \\
Family & -0.0244 & -0.38 \\
Education & 0.1516 & $5.26^{\#}$ \\
Income & 0.0812 & $2.27^{* *}$ \\
Spike & 0.3343 & $22.60^{\#}$ \\
Mean additional WTP per & KRW 30.70 (USD 0.027) \\
kWh & \multicolumn{2}{c}{ 20.53 \# }
\end{tabular}

$t$-value

$95 \%$ confidence interval ${ }^{c}$

KRW 27.90 to 33.81 (USD 0.025 to 0.030 )

$99 \%$ confidence interval ${ }^{c}$

KRW 27.10 to 34.89 (USD 0.024 to 0.031 )

Wald statistic ( $p$-value) ${ }^{\mathrm{d}}$

Log-likelihood

$421.56(0.000)$

$-1013.40$

Number of observations

1000

Notes: a Table 3 explains the variables. ${ }^{\mathrm{b}}$ The unit is KRW 1000 (USD $1.0=$ KRW 1125 at the time of the survey).

${ }^{\mathrm{c}}$ It is calculated using the bootstrapping technique given in Krinsky and Robb [36]. ${ }^{\mathrm{d}}$ It is computed under the null hypothesis of all the parameters' being jointly zero; ** and \# imply statistical meaningfulness at the $5 \%$ and $1 \%$ levels, respectively.

\subsection{Discussion of the Results}

To investigate the public's preference for shifting from coal to NG for electricity in order to abate PM emissions, we estimated an average additional WTP for consuming $1 \mathrm{kWh}$ of electricity produced from NG over coal. The most important issue in the estimation process is whether the sample represents the population. Therefore, it is important to examine whether some sample variables are similar to those for the population. Considering this, the current study investigated the ratio of female respondents and the household's monthly income. The sample averages for the variables were $50.0 \%$ and KRW 4.40 million. The population averages were $50.0 \%$ and KRW 4.38 million when the survey was conducted [33]. Interestingly, it seems that there were no significant differences between the two values for each variable. This finding made the representativeness of our sample even stronger.

How the covariates are selected may affect the WTP estimate. Therefore, the WTP used in this article was derived from a model with no covariates. The average additional WTP for the shift was KRW 31.27 (USD 0.028) per $1 \mathrm{kWh}$. This corresponds to $28.8 \%$ of the average price of electricity, KRW 108.50 (USD 0.096) per $\mathrm{kWh}$ in 2017. The $95 \%$ and the $99 \%$ confidence intervals for the mean additional WTP for the shift were KRW 28.63-34.12 (USD 0.025-0.030) and KRW 27.79-35.08 (USD 0.025-0.031) per $1 \mathrm{kWh}$, respectively. In this regard, it can be concluded that the South Korean public has a significant additional WTP for the shift.

The additional WTP reflects the present values of the public future cost savings related to abatement of PM emissions. If the additional cost involved in electricity produced from NG-fired generation can significantly mitigate PM emissions by replacing coal-fired generation is less than the additional WTP, and also considering the resulting environmental benefits related to the abatement of PM emissions, then shifting from coal to NG for power generation can be successfully conducted. Coal-fired generation was responsible for about half of electricity generation in South Korea in 2017. Because coal is cheaper than NG, it is hard to increase NG instead of coal for power generation. In addition, it is also a problem that the tax on NG, which emits less PM, is much higher than coal. Thus, the government needs to charge tax differentially on the energy sources to substitute a part of the coal-fired electricity generation with NG-fired electricity generation. 


\section{Conclusions}

In South Korea, as PM emitted from coal-fired electricity generation has increased recently, there is concern about the damage this is doing to people's health. The amount of PM emissions from NG-fired electricity generation is about 55 times smaller than that from old coal-fired generation and six times smaller than that from new coal-fired generation [3]. For the purpose of abating PM emissions, the South Korean government has made a plan to shift from coal to NG for power generation. This study applied a CV technique to assessing the interviewees' additional WTP for the shift. The estimate for the mean WTP for the shift was KRW 31.27 (USD 0.028) per $1 \mathrm{kWh}$, and is statistically meaningful. Moreover, our sample represented the population well. Interestingly, this value amounts to $28.8 \%$ of the average price of electricity. The interviewees were willing to pay a significant amount for consuming $1 \mathrm{kWh}$ of electricity produced from NG over coal.

The generation costs are KRW 78.05 per $1 \mathrm{kWh}$ of coal and KRW 100.13 per $1 \mathrm{kWh}$ of NG. The gap between the two generation costs is KRW 22.08 per $1 \mathrm{kWh}$, and this value is smaller than the mean WTP, which is KRW (USD 0.028) per $1 \mathrm{kWh}$. This means that interviewees are willing to pay more than the actual additional generation costs of NG compared to coal. Thus, it is obvious that the governmental policy of shifting from coal to NG power generation to abate PM emissions is supported by the public and that the shift should be made gradually. An important observation emerged from the results in this study. The government and industry should be aware of how interviewees perceive the additional WTP for shifting from coal to NG for power generation. For example, it is encouraged to replace a part of coal-fired generation with NG-fired generation because the interviewees gave higher value to electricity produced from NG over coal.

The authors believe that this study provides the following contributions. To the best of the authors' knowledge, little research has dealt with the issue. This article adds a contribution to the current literature by deriving the additional WTP for shifting from coal to NG for power generation to abate PM emissions. This study provides empirical evidence that the CV approach, theoretically grounded in microeconomics, could be successfully utilized in measuring the additional WTP.

It is costly to shift from coal to NG for power generation with the goal to abate PM emissions by carrying out the plan and through investment. Because the cost will eventually be covered by the electricity bill levied on people, it is vital to gather public opinion on whether or not to pay for the shift. This is because the shift cannot be successful without public support for the shift. In particular, policy makers should ask for quantitative information about people's willingness to pay for the shift. The purpose of this study was to give this information to the policy makers. Therefore, the results from the current study are useful from the perspective of policy-making, as it found that people are willing to pay a significant amount for the shift.

The authors believe that the framework of the study can be extended in future studies in several ways. For example, we need to examine how the value varies as time passes by conducting the $\mathrm{CV}$ survey every year for some years and by analyzing the CV data. Investigating how much the value changes across the regions and identifying other geographic factors which affect the value are also good research topics. Comparing the findings from this study with those from other studies that were completed in different countries and analyzing the gap between them would enable us to obtain new insight into the WTP estimate. These works can provide us with a new point of view in regard to additional WTP.

Author Contributions: All the authors participated in this article. Hyo-Jin Kim proposed the key ideas and quantitatively looked into the data; Ju-Hee Kim conducted a literature review and prepared about half of the paper; Seung-Hoon Yoo made the survey questionnaire, formulated the WTP model, and derived the implications of the study results.

Acknowledgments: This work was supported by the Korea Institute of Energy Technology Evaluation and Planning (KETEP) and the Ministry of Trade, Industry \& Energy (MOTIE) of the Republic of Korea (No. 20164030201060).

Conflicts of Interest: The authors declare no conflict of interest. 


\section{References}

1. Korea Electric Power Corporation. Statistics of Electric Power in Korea. 2017. Available online: http:/ / home. kepco.co.kr (accessed on 20 February 2018).

2. Press Releases of Ministry of Environment: Sejong-si, Korea. 2017. Available online: http://www.me.go.kr (accessed on 20 February 2018). (In Korean)

3. Press Releases of Ministry of Trade, Industry and Energy: Sejong-si, Korea. 2017. Available online: http:/ / www.motie.go.kr (accessed on 20 February 2018). (In Korean)

4. World Health Organization. 7 Million Premature Deaths Annually Linked to Air Pollution. 2014. Available online: http:/ / www.who.int/mediacentre/news/releases/2014/air-pollution/en (accessed on 20 October 2017).

5. International Agency for Research on Cancer. Outdoor Air Pollution a Leading Environmental Cause of Cancer Deaths. 2013. Available online: https:/ / www.iarc.fr/index.php (accessed on 20 February 2018).

6. Achillas, C.; Vlachokostas, C.; Moussiopoulos, N.; Banias, G. Prioritize strategies to confront environmental deterioration in urban areas: Multicriteria assessment of public opinion and experts' views. Cities 2011, 28, 414-423. [CrossRef]

7. Węziak-Białowolska, D. Quality of life in cities-Empirical evidence in comparative European perspective. Cities 2016, 58, 87-96. [CrossRef]

8. Wong, L.P.; Alias, H.; Aghamohammadi, N.; Ghadimi, A.; Sulaiman, N.M.N. Control measures and health effects of air pollution: A survey among public transportation commuters in Malaysia. Sustainability 2017, 9, 1616. [CrossRef]

9. Nguyen, T.N.; Park, D.; Lee, Y.; Lee, Y.C. Particulate matter $\left(\mathrm{PM}_{10}\right.$ and $\left.\mathrm{PM}_{2.5}\right)$ in subway systems: Health-based economic assessment. Sustainability 2017, 9, 2135. [CrossRef]

10. Shaughnessy, W.J.; Venigalla, M.M.; Trump, D. Health effects of ambient levels of respirable particulate matter (PM) on healthy, young-adult population. Atmos. Environ. 2015, 123, 102-111. [CrossRef]

11. Xing, Y.F.; Xu, Y.H.; Shi, M.H.; Lian, Y.X. The impact of PM2.5 on the human respiratory system. J. Thorac. Dis. 2016, 8, 69-74.

12. Dominici, F.; Peng, R.D.; Bell, M.L.; Pham, L.; McDermott, A.; Zeger, S.L.; Samet, J.M. Fine particulate air pollution and hospital admission for cardiovascular and respiratory diseases. J. Am. Med. Assoc. 2006, 295, 1127-1134. [CrossRef] [PubMed]

13. Zanobetti, A.; Franklin, M.; Koutrakis, P.; Schwartz, J. Fine particulate air pollution and its components in association with cause-specific emergency admissions. Environ. Health 2009, 8, 58. [CrossRef] [PubMed]

14. Kim, H.K.; Kang, K.M.; Kim, T.Y. Measurement of particulate matter $\left(\mathrm{PM}_{2.5}\right)$ and health risk assessment of cooking-generated particles in the kitchen and living rooms of apartment houses. Sustainability 2018, 10, 843. [CrossRef]

15. Harris, B.; Kang, B.S. South Korea Joins Ranks of World's Most Polluted Countries. Financial Times. 29 March 2017. Available online: https:/ / www.ft.com/content/b49a9878-141b-11e7-80f4-13e067d5072c (accessed on 20 October 2017).

16. Organization for Economic Co-Operation and Development. Exposure to PM2.5 in Countries and Regions. 2017. Available online: http:/ / stats.oecd.org/index.aspx?queryid=72722 (accessed on 20 October 2017).

17. Min, S.H.; Lim, S.Y.; Yoo, S.H. Consumer's willingness to pay a premium for eco-labeled LED TVs in Korea: A contingent valuation study. Sustainability 2017, 9, 814.

18. Park, S.Y.; Lim, S.Y.; Yoo, S.H. The economic value of the national meteorological service in the Korean household sector: A contingent valuation study. Sustainability 2016, 8, 834. [CrossRef]

19. Lim, S.Y.; Kim, H.Y.; Yoo, S.H. Public willingness to pay for transforming Jogyesa Buddhist temple in Seoul, Korea into a cultural tourism resource. Sustainability 2016, 8, 900. [CrossRef]

20. Kim, H.Y.; Park, S.Y.; Yoo, S.H. Public acceptability of introducing a biogas mandate in Korea: A contingent valuation study. Sustainability 2016, 8, 1087. [CrossRef]

21. Wang, J.; Ge, J.; Ma, Y. Urban Chinese consumers' willingness to pay for pork with certified labels: A discrete choice experiment. Sustainability 2018, 10, 603. [CrossRef]

22. Yang, H.J.; Lim, S.Y.; Yoo, S.H. The environmental costs of photovoltaic power plants in South Korea: A choice experiment study. Sustainability 2017, 9, 1773. [CrossRef]

23. Vanstockem, J.; Vranken, L.; Bleys, B.; Somers, B.; Hermy, M. Do looks matter? A case study on extensive green roofs using discrete choice experiments. Sustainability 2018, 10, 309. [CrossRef] 
24. Wang, Y.; Zhang, Y.S. Air quality assessment by contingent valuation in Ji'nan, China. J. Environ. Manag. 2009, 90, 1022-1029. [CrossRef] [PubMed]

25. Lee, J.Y.; Lim, Y.W.; Yang, J.Y.; Kim, C.S.; Shin, Y.C.; Shin, D.C. Evaluating the PM damage cost due to urban air pollution and vehicle emissions in Seoul, Korea. J. Environ. Manag. 2011, 92, 603-609. [CrossRef] [PubMed]

26. Rizzi, L.I.; De La Maza, C.; Cifuentes, L.A.; Gómez, J. Valuing air quality impacts using stated choice analysis: Trading off visibility against morbidity effects. J. Environ. Manag. 2014, 146, 470-480. [CrossRef] [PubMed]

27. Wang, J.; Wang, S.; Voorhees, A.S.; Zhao, B.; Jang, C.; Jiang, J.; Fu, J.S.; Ding, D.; Zhu, Y.; Hao, J. Assessment of short-term $\mathrm{PM}_{2.5}$-related mortality due to different emission sources in the Yangtze River Delta, China. Atmos. Environ. 2015, 123, 440-448. [CrossRef]

28. Tang, C.; Zhang, Y. Using discrete choice experiments to value preferences for air quality improvement: The case of curbing haze in urban China. J. Environ. Plan. Manag. 2016, 59, 1473-1494. [CrossRef]

29. Wei, W.; Yan, W. Willingness to pay to control $\mathrm{PM}_{2.5}$ pollution in Jing-Jin-Ji Region, China. Appl. Econ. Lett. 2017, 24, 753-761. [CrossRef]

30. Champ, P.A.; Boyle, K.J.; Brown, T.C.A. Primer on Nonmarket Valuation; Kluwer Academic Publisher: Dordrecht, The Netherlands, 2004.

31. Hanemann, W.M. Welfare evaluations in contingent valuation experiments with discrete responses. Am. J. Agric. Econ. 1984, 66, 332-341. [CrossRef]

32. Kriström, B. Spike model in contingent valuation. Am. J. Agric. Econ. 1997, 79, 1013-1023. [CrossRef]

33. Statistics Korea. Available online: http:/ / kosis.kr (accessed on 30 December 2017).

34. Hanemann, W.M.; Loomis, J.; Kanninen, B.J. Statistical efficiency of double-bounded dichotomous choice contingent valuation. Am. J. Agric. Econ. 1991, 73, 1255-1263. [CrossRef]

35. Johnston, R.J.; Boyle, K.J.; Adamowicz, W.; Bennett, J.; Brouwer, R.; Cameron, T.A.; Hanemann, W.M.; Hanley, N.; Ryan, M.; Scarpa, R.; et al. Contemporary guidance for stated preference studies. J. Assoc. Environ. Resour. Econ. 2017, 4, 319-405. [CrossRef]

36. Krinsky, I.; Robb, A.L. On approximating the statistical properties of elasticities. Rev. Econ. Stat. 1986, 68, 715-719. [CrossRef] 